\title{
Heart Chamber Volume at End Ventricular Systole
}

National Cancer Institute

\section{Source}

National Cancer Institute. Heart Chamber Volume at End Ventricular Systole. NCI

Thesaurus. Code C135373.

The volume of blood remaining in a heart chamber at end ventricular systole. 